OPEN ACCESS

Edited by:

Santosh Kumar Yadav,

Drexel University, USA

Reviewed by:

Ashok K. Sundramoorthy

University of Wisconsin-Madison,

USA

Yoong Ahm Kim,

Chonnam National University,

South Korea

${ }^{*}$ Correspondence:

Junfeng Geng

j.geng@bolton.ac.uk

Specialty section:

This article was submitted to

Carbon-Based Materials,

a section of the journal

Frontiers in Materials

Received: 24 November 2015 Accepted: 21 January 2016

Published: 22 February 2016

Citation:

Geng J, Motta M, Engels V, Luo J and Johnson BFG (2016)

Temperature Threshold and Water Role in CVD Growth of Single-Walled

Carbon Nanotubes.

Front. Mater. 3:4.

doi: 10.3389/fmats.2016.00004

\section{Temperature Threshold and Water Role in CVD Growth of Single-Walled Carbon Nanotubes}

\author{
Junfeng Geng ${ }^{1,2,3 \star}$, Marcelo Motta ${ }^{4}$, Volker Engels ${ }^{5}$, Jikui Luo ${ }^{1,2}$ and Brian F. G. Johnson ${ }^{3}$ \\ ${ }^{1}$ Institute for Materials Research and Innovation, University of Bolton, Bolton, UK, ${ }^{2}$ Institute for Renewable Energy and \\ Environmental Technologies, University of Bolton, Bolton, UK, ${ }^{3}$ Department of Chemistry, University of Cambridge, \\ Cambridge, UK, ${ }^{4}$ Thomas Swan \& Co. Ltd., Consett, UK, ${ }^{5}$ School of Chemistry, University of St. Andrews, St. Andrews, UK
}

An in-depth understanding of the growth process of single-walled carbon nanotubes is of vital importance to the control of the yield of the material and its carbon structure. Using a nickel/silica (Ni/SiOx) catalyst, we have conducted a series of growth experiments with a chemical vapor deposition (CVD) system. We find that there is a temperature threshold in the CVD process, and if the reaction temperature sets above this threshold, there will be no growth of the nanotubes. Moreover, we find that in association with this temperature effect, water plays an important role in the promotion or termination of the growth of single-walled carbon nanotubes.

Keywords: single-walled carbon nanotubes, nickel catalyst, chemical vapor deposition, nanotube growth, temperature effect, water role

\section{INTRODUCTION}

Catalysts are important for growing carbon-based nanomaterials, such as carbon nanotubes. Traditionally, nanoparticulate metals, especially $\mathrm{Fe}, \mathrm{Co}$, and $\mathrm{Ni}$, have been used as the catalysts due to the high solubility and diffusion rate of carbon in these metals. However, Rümmeli et al. (2005) reported that metal oxides could be used as catalyst for growing single-walled carbon nanotubes (SWCNTs) with laser ablation technique. In addition, a report by Takagi et al. (2007) shows that even semiconductor nanoparticles, such as $\mathrm{SiC}, \mathrm{Ge}$, and $\mathrm{Si}$, can be used as the catalyst. This implies that a range of nanosize structures could act as a template for the formation of SWCNTs. Furthermore, an entirely catalyst-free growth has been proven possible on porous alumina substrates (Kusunoki et al., 2000; Bae et al., 2002; Schneider et al., 2008).

The growth of carbon nanotubes has been shown to continue even when the metal particle is encapsulated by graphene, suggesting a possible role of oxygen as a promoter for the addition of further carbon atoms to the base of the growing tube (Rümmeli et al., 2007). Subsequent reports by Wen et al., 2007 which found a better control over the tube morphology upon the addition of oxygen to the precursor gas stream, suggest a role of oxygen in the formation of radical species reducing amorphous carbon depositions in the case of $\mathrm{O}_{2}$-assisted methane decomposition (Bandow et al., 1998; Sundramoorthy et al., 2013; Mesgari et al., 2014). More recently, silica support systems are attracting growing attention. To this end, the studies by Liu et al. (2009a,b,2011) demonstrated the activity of $\mathrm{SiO}_{x}$ nanoparticles for the promotion of CNT growth. Moreover, the authors suggested that $\mathrm{SiO}_{\mathrm{x}}$ nanoparticles remain solid during the growth process, hinting a vapor-solid-solid (VSS) growth mechanism. 
As early as in 1996, Tohji et al. (1996) showed that a water sonication of raw nanotubes made by the arc-discharge technique could be an effective method for purifying SWCNTs. After initially reporting a water-assisted synthesis of Si-supported single-walled nanotubes, Hata et al. (2004) claimed that water acted as an oxidizing agent for amorphous carbon, following a similar idea for $\mathrm{O}_{2}$-assisted growth (Yamada et al., 2008). A report by Min et al. (2005) confirmed the effect of water for the selectivity of SWCNTs over multiwalled nanotubes (MWCNTs) growth, in agreement with the initial observation of Tohji. Following the reports on the effect of $\mathrm{CO}_{2} / \mathrm{H}_{2} \mathrm{O}$ mixtures (Nasibulin et al., 2006a,b), Pint et al. (2009) discussed the issue of the nanocatalyst stability. The authors suggested that the water-generated surface-bound hydroxyl species might prevent the growth of the particle through ripening, which as a kinetic process, has been previously proven to be effective in promotion of nanotube growth (Kim et al., 2009) and allows an improved overall control over tube monodispersity.

Following our previous reports on chemical vapor deposition (CVD) growth of SWCNTs (Geng et al., 2002, 2004, 2005, 2006; Kleinsorge et al., 2004; Li et al., 2004; Golovko et al., 2005; Hofmann et al., 2005; Engels et al., 2011), we wish to develop an in-depth understanding of the role of water in the growth process. Here, we report that using a catalytic $\mathrm{Ni} / \mathrm{SiO}_{\mathrm{x}}$ system, which is also supported by other catalytic systems, including $\mathrm{Fe} /$ $\mathrm{MgO}, \mathrm{Fe} / \mathrm{K}_{2} \mathrm{CO}_{3}, \mathrm{Ni} / \mathrm{MgO}, \mathrm{Fe} / \mathrm{NaCl}$, and $\mathrm{Ni} / \mathrm{NaCl}$, as shown in this work, there is a threshold temperature in the CVD growth of single-walled carbon nanotubes. If the reaction temperature is above the threshold, the growth will be terminated. In addition, all the experimental data suggest the important role of water in the promotion of the nanotube growth. In comparison with $\mathrm{Ni}$-films $/ \mathrm{SiO}_{2} / \mathrm{Si}$ wafer systems prepared by physical evaporation or magnetron sputtering, the $\mathrm{Ni} / \mathrm{SiO}_{\mathrm{x}}$ catalyst employed in this work was prepared by a wet chemistry route, which is relatively less explored in terms of the investigation of the roles of water. Since the wet chemistry route is of low cost and relatively easier to scale up, it represents one of the major techniques adopted presently by the industry for commercial production of SWCNTs. An in-depth understanding of the role of water in such a system is hence critically important for the industrial process in order to achieve the highest possible nanotube growth yield and the best control of the carbon nanostructure.

\section{EXPERIMENTAL}

For the catalyst synthesis, $5 \mathrm{~g}$ of fumed silica (Sigma-Aldrich product) was typically mixed with $200 \mathrm{ml}$ aqueous solution of nickel formate dihydrate $(c=1.5 \mathrm{mg} / \mathrm{ml})$, equivalent to a maximum $\mathrm{Ni}$ loading of $1.9 \mathrm{wt} \%$ relative to silica. Depending on the growth purpose, the metal loading value may be varied. The mixture was vigorously stirred at $70^{\circ} \mathrm{C}$ for about $20 \mathrm{~h}$ before it was dried in oven first at $90^{\circ} \mathrm{C}$ for $24 \mathrm{~h}$ and subsequently at $120^{\circ} \mathrm{C}$ for $3 \mathrm{~h}$. The dried samples were carefully ground by agitate mortar. The Ni catalyst nanoparticles were formed in situ in the CVD growth process via the thermal decomposition of the formate precursor.

Growths of SWCNTs were performed using a thermal CVD equipped with a quartz reactor and a temperature control unit. The CVD was set in a fume hood equipped with an Argon (Ar) gas line. For each experiment, the reactor was first heated to the desired temperature $\left(700-1100^{\circ} \mathrm{C}\right)$ under a flow of Ar. When the system stabilized at the target temperature, a quartz boat containing the catalyst was placed in the center of the tube reactor. Immediately afterwards, methane gas $\left(\mathrm{CH}_{4}\right)$ was introduced into the reactor as carbon feedstock. A typical gas flow rate was $1.0 \mathrm{l} /$ min for $\mathrm{Ar}$ and $0.3 \mathrm{l} / \mathrm{min}$ for $\mathrm{CH}_{4}$. The growth time was $20 \mathrm{~min}$ for each run.

Scanning electron microscopy (SEM) characterization was performed using a JEOL 6340-FESEM system operated at $5 \mathrm{kV}$ for the as-made products without any metal coating. Transmission electron microscopic (TEM) examinations were conducted with a $2100 \mathrm{~F}$ FEG TEM system operated at $200 \mathrm{kV}$. TEM samples were prepared by ultra-sonication of toluene-suspended carbon nanotubes and the subsequent dispersion of the sample onto TEM Cu grid (Agar Scientific, holey carbon film, 300 mesh). Energy dispersive X-ray spectroscopy (EDX) was used to analyze the elemental composition of the catalysts. In addition, scanning transmission electron microscopy (STEM) was employed to examine the metal nanoparticles and SWCNTs in both bright and dark fields.

Laser Raman measurements were conducted using microRaman spectrometers with varied laser excitation wavelengths $(\lambda=488,514.5,568$, and $633 \mathrm{~nm}$, respectively). Each apparatus was equipped with a microscope, a video camera, and the Renishaw software. A spectral resolution of $0.1 \mathrm{~cm}^{-1}$ and a laser spatial resolution of $1.0 \mu \mathrm{m}$ were applied to the measurements. Water contents in the catalytic supports were measured by elemental analysis (EA), with which the samples were burned in a pure oxygen atmosphere followed by a quantitative analysis of hydrogen through the measurement of the changes of thermal conductance of a Pt wire using a CE 440 Elemental Analyzer. The SWCNTs yield was also measured by this method via a quantitative analysis of carbon from product $\mathrm{CO}_{2}$ after burning the carbon nanotube samples in oxygen. Thermal gravimetric analysis (TGA) was carried out using a Mettler Toledo TGA/DSC Star System with a heating rate of $10^{\circ} \mathrm{C} / \mathrm{min}$ and temperatures of up to $900^{\circ} \mathrm{C}$, in both air and nitrogen atmospheres.

\section{RESULTS AND DISCUSSION}

While SEM images of the as-grown carbon nanotubes (Figure 1) showed a quite abundant growth activity on the silica support, high-resolution TEM analysis (Figure 2A) revealed that the product was single walled, mainly in the form of small bundles. A large number of small particles (1-2 nm), located mainly within the nanotube bundles, were also observed. These nanoparticles were believed to be the Ni catalysts which had assisted the nanotube nucleation and the growth. To confirm this, the nanoparticles were further examined by STEM in both bright and dark-field modes (Figures $\mathbf{2 B}, \mathbf{C}$ ) as the dark-field analysis allowed an additional surface information to be obtained from the higher contrast of the nickel relative to the carbon background.

The EDX spectra (in Figure 2) showed the presence of both $\mathrm{K}$ and $\mathrm{L}$ edges of the nickel. A strong oxygen K-edge turned up from the particles sitting on top of $\mathrm{SiO}_{\mathrm{x}}$ support, no such a signal could be observed from those particles embedded within 

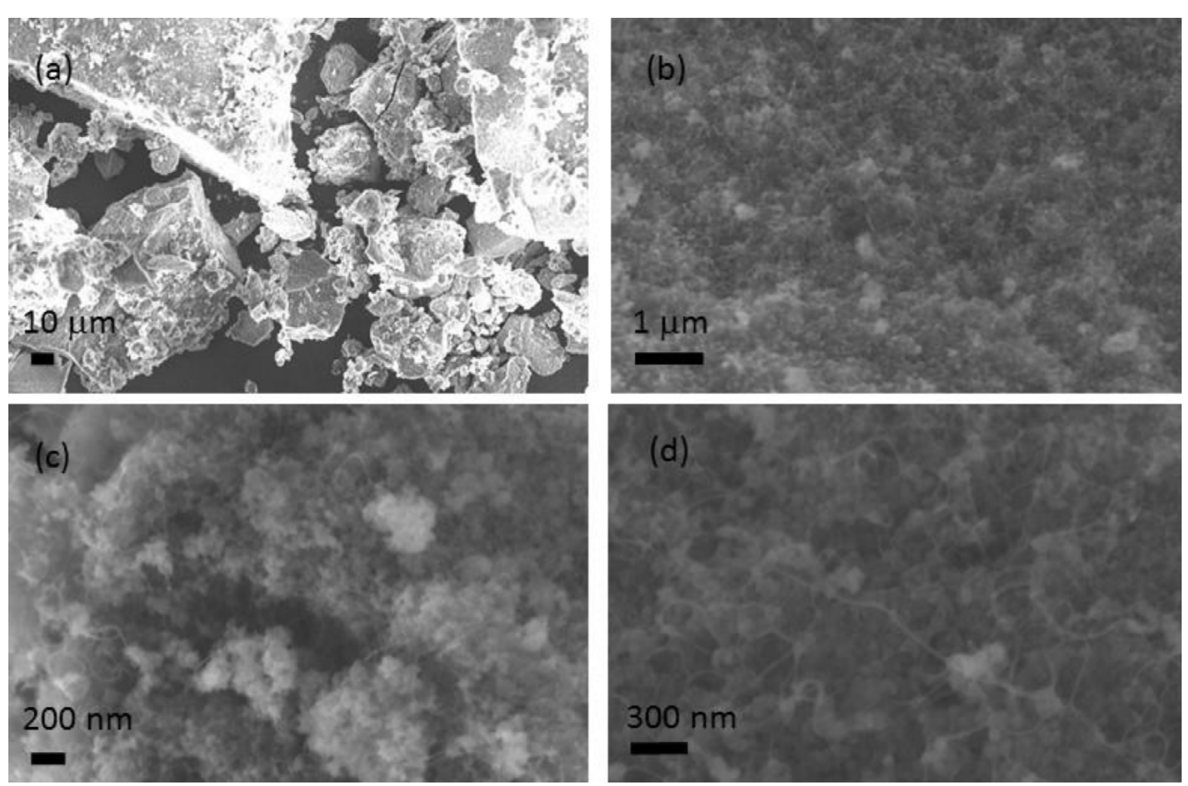

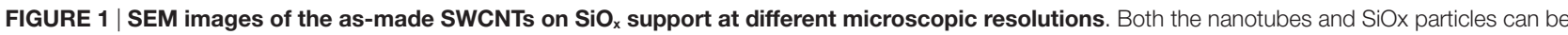
seen from the images. From (A-D) the images of the same sample with gradually increased resolutions.
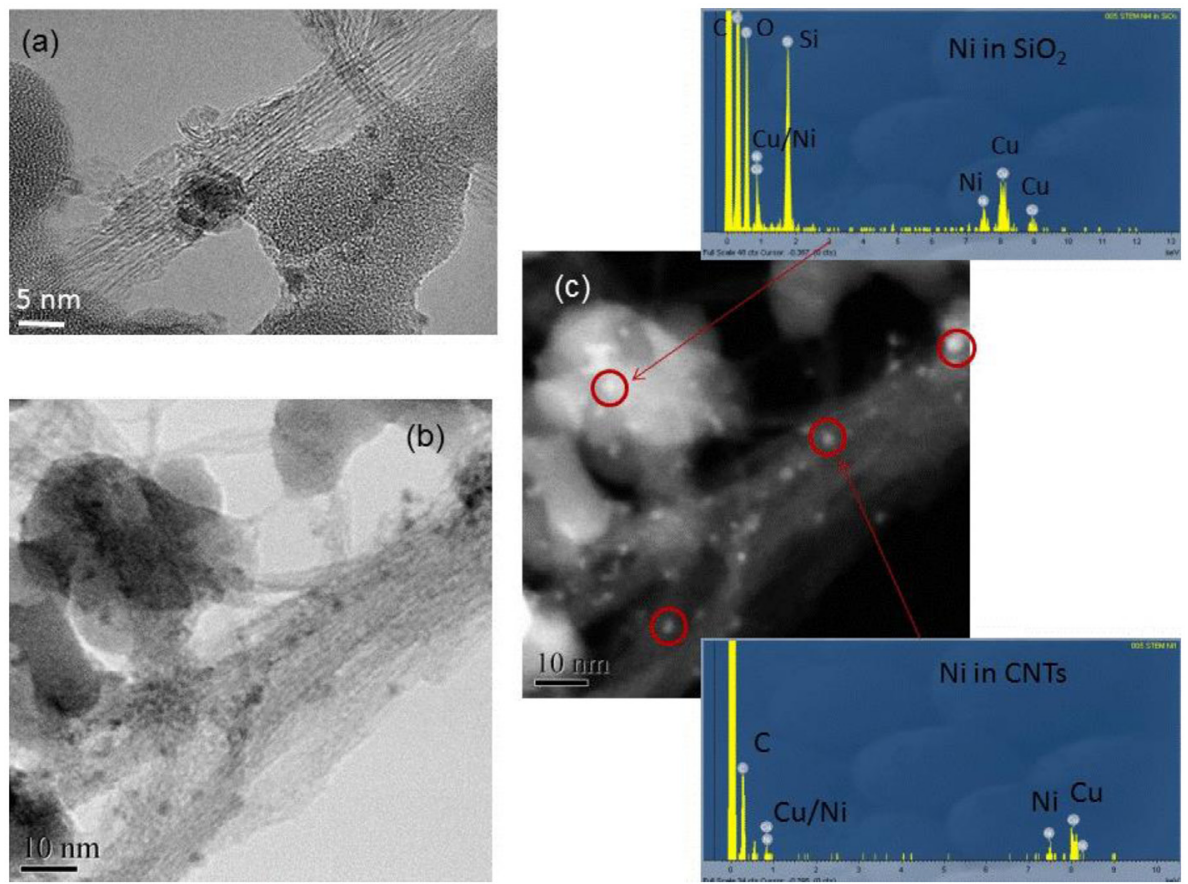

FIGURE 2 | (A) TEM image of the as-made SWCNTs on silica support; (B) STEM image of the SWCNTs in bright field; (C) STEM image of the area shown in (B) in dark field. The EDX spectra were acquired from the nanoparticles circled in red in (C).

nanotube bundles. Clearly, these analyses allow us to conclude that the nanoparticles are indeed metallic $\mathrm{Ni}$, and the oxygen $\mathrm{K}$-edge signal is from the oxide support. The nanotube yield was estimated by EA. For example, with a CVD growth operated at
$T=920^{\circ} \mathrm{C}$ for 20 min using $\mathrm{Ni} / \mathrm{SiOx}$ as catalyst/support, the nanotube yield was measured as $2.47 \mathrm{wt} \%$ relative to the catalyst/ support. As catalytic Ni\% loading was $1.9 \mathrm{wt} \%$ on silica support in this case, the nanotube yield can also be calculated as $130 \mathrm{wt} \%$ 
relative to the pure metal loading, which means that each $100 \mathrm{~g}$ of Ni had produced $130 \mathrm{~g}$ of SWCNTs.

Figure 3 shows an example of Raman spectra recorded from the as-prepared samples at different excitation wavelengths. While the D peak $\left(\sim 1354 \mathrm{~cm}^{-1}\right)$ remains comparably weak, the strong $\mathrm{G}$ peak is composed of three components typically associated with SWCNTs $\left(\sim 1525,1545\right.$, and $1591 \mathrm{~cm}^{-1}$, respectively, in this case). The small ratio of the intensities of $\mathrm{D}$ to $\mathrm{G}\left(I_{\mathrm{D}} / I_{\mathrm{G}} \approx 0.16\right)$ indicates a low level of defects in the product. Depending on the wavelength of the excitation laser, the radial breathing modes $(\mathrm{RBM})$ were observed in the region between 148 and $300 \mathrm{~cm}^{-1}$. From these modes, which are inversely proportional to the tube diameters $\left[f\left(\mathrm{~cm}^{-1}\right)=223.75 / d(\mathrm{~nm})\right]$ (Bandow et al., 1998; Sundramoorthy et al., 2013; Mesgari et al., 2014), the tube diameters were estimated to be in the region of $0.76-1.51 \mathrm{~nm}$, with an average diameter of $1.14 \mathrm{~nm}$.

To obtain in-depth understanding of the nanotube growth process, we performed a series of CVD growths at different reaction temperatures starting from $720^{\circ} \mathrm{C}$. These experiments were based on a set of preliminary growth tests with the same catalyst. Figure 4 shows the result of the Raman characterization of the products. As can be seen from Figure 4, the Raman profiles are almost the same for samples made below $T=920^{\circ} \mathrm{C}$ in terms of the scattering positions. Moreover, all the profiles clearly show the characteristic of SWCNTs. It was noticed that even if the samples were irradiated by $100 \%$ powered laser for $8 \mathrm{~min}$, the recorded spectra underwent no any noticeable change at all. This observation, together with the low D/G ratios, suggests that the nanotubes are highly robust in their graphitic structure and have an excellent quality. However, when the CVD temperature was raised to $970^{\circ} \mathrm{C}$, the Raman profiles started displaying stronger $\mathrm{D}$ peaks and weaker RBM. If the temperature was further raised to $1050^{\circ} \mathrm{C}$, no $\mathrm{RBM}$ could be observed, which indicates that no SWCNTs were produced in the CVD. Instead, the typical feature

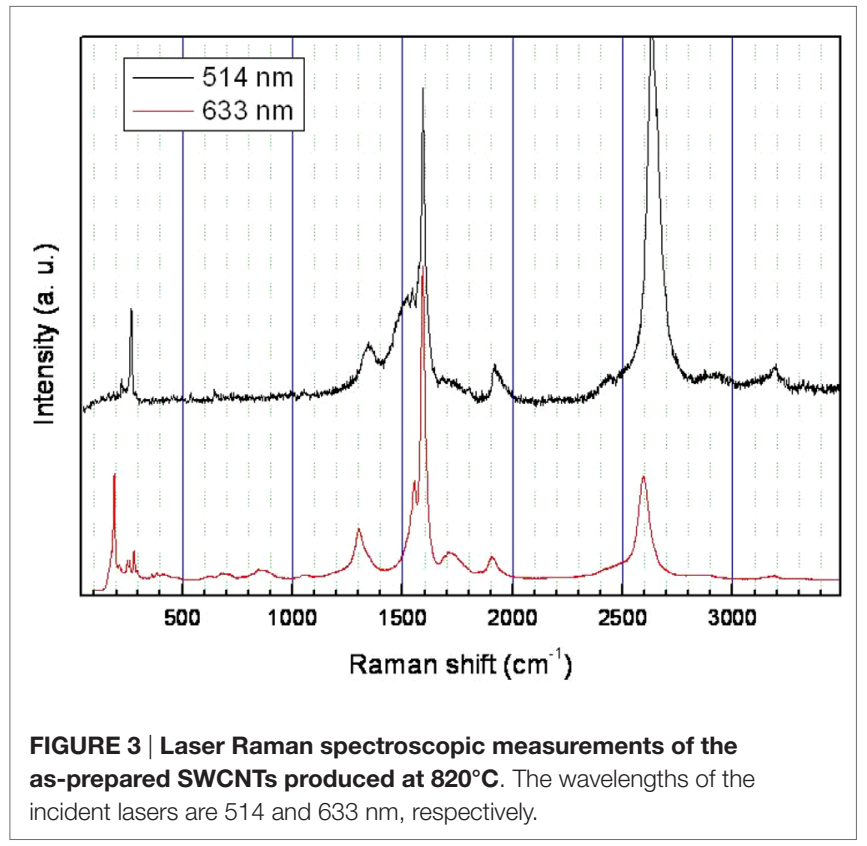

of carbon nanofibres appeared, i.e., a wider and stronger D peak and a large $\mathrm{D} / \mathrm{G}$ ratio approaching to 1.0 . This indicates that there is a threshold temperature in the CVD growth system: if the reaction temperature is above the threshold, there will be no growth of SWCNTs. In this work, such a threshold temperature is estimated to be about $970^{\circ} \mathrm{C}$.

This temperature-dependence phenomenon prompts us to investigate the underlying reason. We noted that the silica supporting material employed in this work contained water in the microporous structure and the water is removable by calcining the material at $T>900^{\circ} \mathrm{C}$. Moreover, since the catalysts were prepared in aqueous solutions, the preparation process allowed a further intake of $\mathrm{H}_{2} \mathrm{O}$ into the porous $\mathrm{SiO}_{\mathrm{x}}$. The water could not be totally removed from the supports before CVD growth although the materials were dried by oven at $90^{\circ} \mathrm{C}$ for $24 \mathrm{~h}$ and subsequently at $120^{\circ} \mathrm{C}$ for $3 \mathrm{~h}$ (also see TGA and EA below). Could a small amount of $\mathrm{H}_{2} \mathrm{O}$ be the reason for promoting the growth of SWCNTs in a suitable temperature range? If so, a complete removal of water from the system could be responsible for the termination of the growth at temperatures above the threshold. To answer this question, we first note that there are already reports on the important effect of water in the growth of SWCNTs such as the case of vertically growing SWCNTs on silicon wafer (Hata et al., 2004; Yamada et al., 2008). In the present case of using porous silica powder support, water is believed to have also played an important role by acting as the growth promoter.

To confirm this view, we measured the water content in the catalyst/support and observed its release process from the microporous structure by performing TGA analysis in both nitrogen and air (Figure 5). In both cases, a major sample weight loss occurred at $\sim 250^{\circ} \mathrm{C}$ due to thermal decomposition of the catalyst precursor, nickel formate (Geng et al., 2002, 2004). Unlike many other $\mathrm{Ni}$-containing salts, this compound decomposes directly into metallic Ni particles and gas species $\left(\mathrm{H}_{2}, \mathrm{H}_{2} \mathrm{O}, \mathrm{CO}\right.$, and $\left.\mathrm{CO}_{2}\right)$ without forming the oxide intermediate $(\mathrm{NiO})$ in a gas flowing system. This makes the normally required reducing agents such as $\mathrm{H}_{2}$ no longer necessary for in situ formation of pure metallic nickel. While the TGA data obtained in air showed a weight increase at temperatures higher than $600^{\circ} \mathrm{C}$ owing to the reoxidation of the Ni nanoparticles, the data obtained in $\mathrm{N}_{2}$ showed a continuous loss of $\mathrm{H}_{2} \mathrm{O}$ until $900^{\circ} \mathrm{C}$, the apparatus's maximum operating temperature. However, this result indicates that water remains in the silica support and cannot be completely removed until at least $900^{\circ} \mathrm{C}$. To further test the water-loss behavior, we heated the catalyst/support in a tube furnace to $1000^{\circ} \mathrm{C}$ in argon for $20 \mathrm{~min}$, and subsequently used EA to determine the residual water amount. Within the experimental error, the water residue level was found to be very low after such a heat treatment, with the resulting $\mathrm{H}=0.09 \mathrm{wt} \%$ corresponding to $\mathrm{H}_{2} \mathrm{O}=0.81 \mathrm{wt} \%$. This suggests that the heat treatment has resulted in almost complete removal of water from the silica at $1000^{\circ} \mathrm{C}$, a result which is consistent with our observation that in the CVD system, the threshold growth temperature is about $970^{\circ} \mathrm{C}$, above this threshold there would be no growth of SWCNTs.

Additional evidence supports the role of water as the growth promoter. In addition to the $\mathrm{Ni} / \mathrm{SiOx}$ system, we prepared a range of catalysts using the same wet chemistry method. Using both 


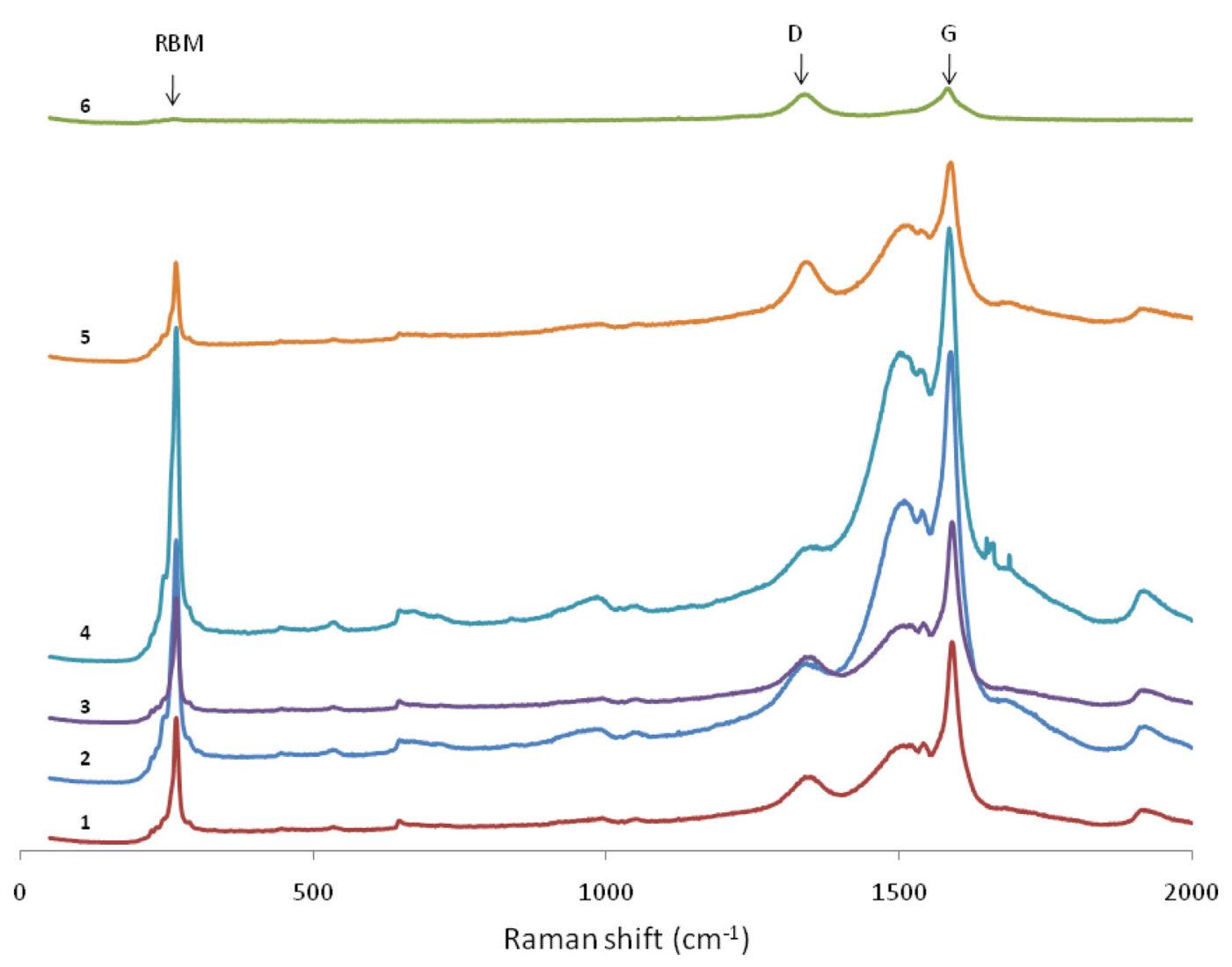

FIGURE 4 | Laser Raman spectra of SWCNTs produced at different CVD temperatures. From 1 to 6 , the reaction temperature corresponds to 720,770 , $820,870,920$, and $970^{\circ} \mathrm{C}$, respectively. In this case, the spectra were obtained from a microspectrometer using an $\mathrm{Ar}^{+}$ion excitation laser at $\lambda=514 \mathrm{~nm}$, with a beam spot $\sim 10 \mu \mathrm{m}$ and the laser output $\sim 15 \mathrm{~mW}$.

water-resistant oxides such as $\mathrm{MgO}$ and $\mathrm{Al}_{2} \mathrm{O}_{3}$, and water-soluble salts such as $\mathrm{NaCl}$ and $\mathrm{K}_{2} \mathrm{CO}_{3}$ as the supports, we prepared the catalysts of $\mathrm{Ni} / \mathrm{NaCl}$ (from nickel stearate, with a number of samples of having a series of metal loadings between 0.005 and $0.5 \mathrm{wt} \%$ ), $\mathrm{Fe} / \mathrm{NaCl}$ (from iron stearate, metal loading $\sim 0.005$ wt\%), $\mathrm{Fe} /$ $\mathrm{K}_{2} \mathrm{CO}_{3}$ (from iron nitrate, metal loading $1.0 \mathrm{wt} \%$ ), $\mathrm{Fe} / \mathrm{MgO}$ (from iron nitrate, a number of samples with a series of metal loadings in between $0.20-0.85 \mathrm{wt} \%$ ), $\mathrm{Ni} / \mathrm{MgO}$ (from nickel formate, a number of samples with a series of metal loadings in between 0.20-2.0 wt\%), and $\mathrm{Fe} / \mathrm{Al}_{2} \mathrm{O}_{3}$ (from iron sulfate, a number of samples with a series of metal loadings in between 0.10-2.0 wt\%). We observed that similar to the $\mathrm{SiOx}$ system, $\mathrm{MgO}$ and $\mathrm{Al}_{2} \mathrm{O}_{3}$ can also be used to efficiently produce SWCNTs under similar CVD conditions. However, despite a great deal of efforts by experimentally varying the catalyst precursors, metal loadings, and CVD reaction conditions, no SWCNTs could be grown with the $\mathrm{NaCl}$ or $\mathrm{K}_{2} \mathrm{CO}_{3}$ system. Further analysis reveals that similar to silica, both $\mathrm{MgO}$ and $\mathrm{Al}_{2} \mathrm{O}_{3}$ powder have a microporous structure, which can help to retain water, and a trace mount of water contained in the pores cannot be completely removed unless a high temperature treatment at $\sim 1000^{\circ} \mathrm{C}$ is applied. However, in contrast to these oxide supports, $\mathrm{NaCl}$ and $\mathrm{K}_{2} \mathrm{CO}_{3}$ are crystalline grains and the crystals have flat and smooth surfaces so they do not have a microporous structure and hence are unable to retain water.
The above tests and analysis clearly support the view that a trace amount of water in the catalytic supporting materials would be crucial to the promotion of SWCNT growth. The acting role of water is still poorly understood at the moment; here, we only intend to tentatively suggest the following mechanism: water could help to etch amorphous carbon away via the water-gas reaction (Cotton and Wilkinson, 1980) at elevated temperatures, $\mathrm{H}_{2} \mathrm{O}+\mathrm{C} \rightarrow \mathrm{CO}+\mathrm{H}_{2}$, as schematically illustrated in Figure 6. In this way, water acts as an oxidizing agent, and the removal of amorphous carbon promotes the growth of single-walled carbon nanotubes. Other mechanistic possibilities could coexist in the CVD system. For example, water could be a source of surface-bound $\mathrm{OH}$ species, which help to prevent the over growth of catalyst nanoparticles through ripening and with this mechanistic process, the growth of single-walled carbon nanotubes is favored (Zhang et al., 2005; Amama et al., 2009; Pint et al., 2009).

\section{CONCLUSION}

We have investigated the CVD growth of single-walled carbon nanotubes using a silica-supported nickel catalyst. We find that there is a temperature threshold in the growth process, and if the reaction temperature is above the threshold, there will be 


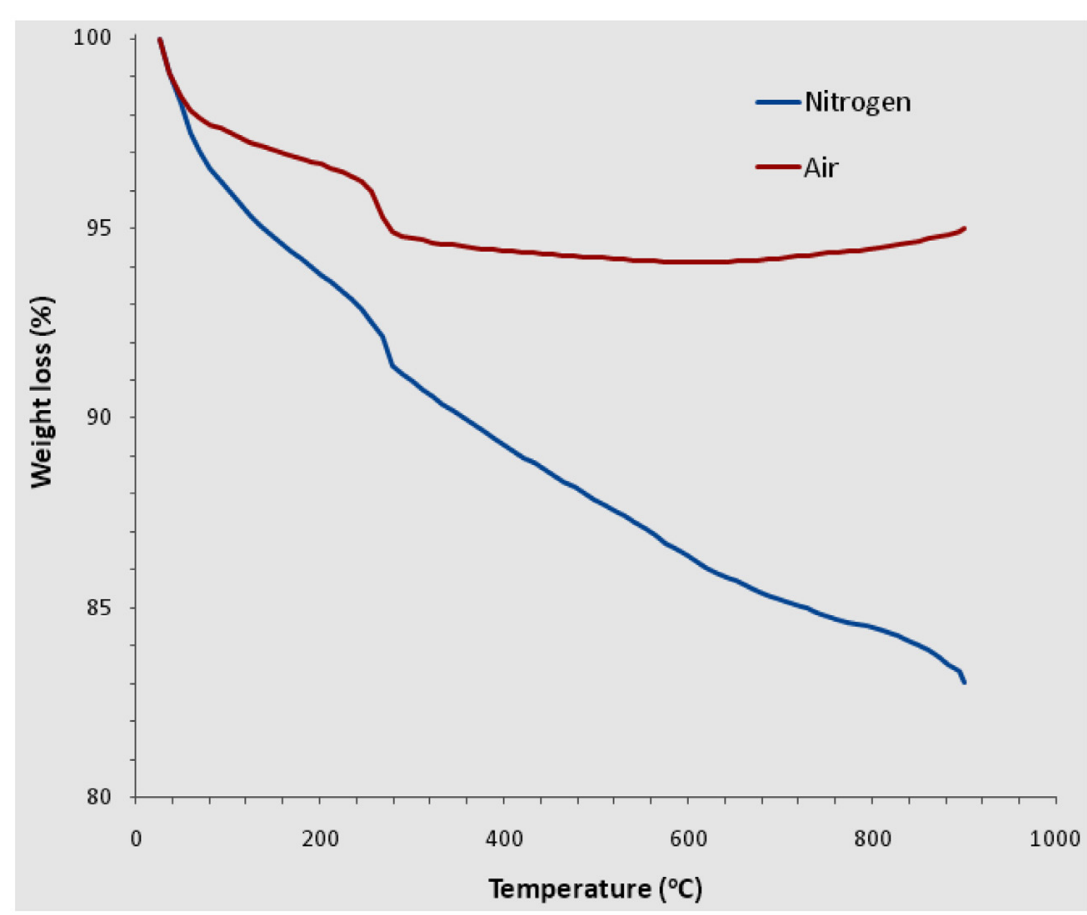

FIGURE 5 | TGA analysis, in both air and nitrogen atmosphere, of the catalyst (nickel formate coated on fumed silica) to show the sample weight loss caused by thermal decomposition of the nickel precursor and the removal of water from the micropores of silica.

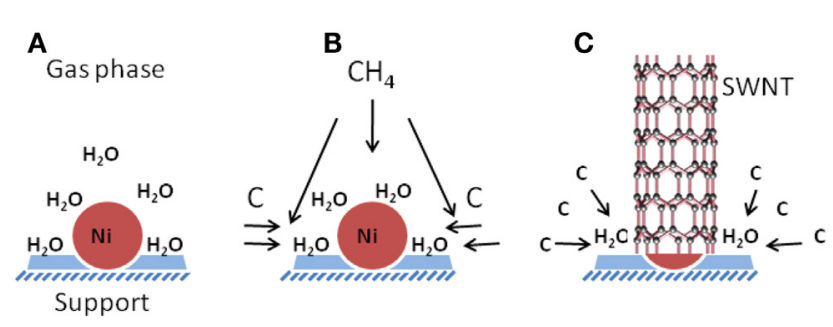

FIGURE 6 | A schematic shows the kinetic growth process of SWCNTs and the associated role of water played as the intermediate between gas phase carbon and nickel catalyst to etch amorphous carbon away. Schematic (A-C) corresponds to the initial state of the catalyst without any carbon feedstock, the introduction of methane gas in the CVD system, and the growth stage of SWCNTs, respectively.

no growth of single-walled carbon nanotubes. Along with the temperature effect, we have analyzed the role of water in the growth process. All the experimental data suggest that water is a necessary component in the CVD process and it promotes the growth of single-walled carbon nanotubes when presented as

\section{REFERENCES}

Amama, P. B., Pint, C. L., Mcjilton, L., Kim, S. M., Stach, E. A., Murray, P. T., et al. (2009). Role of water in super growth of single-walled carbon nanotube carpets. Nano Lett. 9, 44. doi:10.1021/nl801876h

Bae, E. J., Choi, W. B., Jeong, K. S., Chu, J. U., Park, G. S., Song, S., et al. (2002). Selective growth of carbon nanotubes on pre-patterned impurity in the catalytic support. A complete removal of water from the catalyst may lead to termination of the growth. To this end, we believe that an in-depth understanding of the effect of water should be able to provide a guidance for future rational design of catalysts in order to achieve more efficient and structurally better controlled growth of SWCNTs using a relatively simple and low-cost thermal CVD process.

\section{AUTHOR CONTRIBUTIONS}

JG: initiated the project and performed most of the experiments and wrote this paper. MM: performed TEM and TGA tests and coauthored the paper. VE, JL, and BJ: assisted the project, provided helpful discussion, and coauthored the paper.

\section{ACKNOWLEDGMENTS}

The authors wish to acknowledge Dr. Budhika G. Mendis at Durham University, UK, for his assistance with the highresolution electron microscopy work. JG thanks the Knowledge Centre for Materials Chemistry UK for financial assistance.

porous anodic aluminum oxide. Adv. Mater. Weinheim 14, 277. doi:10.1002/1521-4095(20020219)14:4<277::AID-ADMA277>3.0.CO;2-A

Bandow, S., Asaka, S., Saito, Y., Rao, A. M., Grigorian, L., Richter, E., et al. (1998). Effect of the growth temperature on the diameter distribution and chirality of single-wall carbon nanotubes. Phys. Rev. Lett. 80, 3779. doi:10.1103/PhysRevLett.80.3779

Cotton, F. A., and Wilkinson, G. (1980). Advanced Inorganic Chemistry. New York: John Wiley \& Sons, Inc. 
Engels, V., Geng, J., Jones, G. M., Elliott, J. A., Wheatley, A. E. H., and Boss, S. R. (2011). Cobalt catalyzed carbon nanotube growth on graphitic paper supports. Curr. Nanosci. 7, 315. doi:10.2174/157341311795542471

Geng, J., Kinlock, I., Singh, C., Golovko, V. B., Johnson, B. F. G., Shaffer, M. S. P., et al. (2005). Production of carbon nanofibres in high yields using a sodium chloride support. J. Phys. Chem. B 109, 16665. doi:10.1021/jp051544w

Geng, J., Li, H., Golovko, V. B., Shephard, D. S., Jefferson, D. A., and Johnson, B. F. G. (2004). Nickel formate route to the growth of carbon nanotubes. J. Phys. Chem. B 108, 18446. doi:10.1021/jp047898p

Geng, J. F., Li, H. W., Zhou, D. J., Huck, W. T. S., and Johnson, B. F. G. (2006). A dendrimer-based Co32 nanocluster: synthesis and application as catalyst for diameter-controlled growth of single-walled carbon nanotubes. Polyhedron 25, 585. doi:10.1016/j.poly.2005.08.036

Geng, J. F., Singh, C., Shephard, D. S., Shaffer, M. S. P., Johnson, B. F. G., and Windle, A. H. (2002). Synthesis of high purity single-walled carbon nanotubes in high yield. Chem. Commun. (Camb.) 2666-2667. doi:10.1039/b207975p

Golovko, V. B., Li, H. W., Kleinsorge, B., Hofmann, S., Geng, J., Cantoro, M., et al. (2005).Submicron patterning ofCocolloidcatalyst forgrowth ofvertically aligned carbon nanotubes. Nanotechnology 16, 1636. doi:10.1088/0957-4484/16/9/039

Hata, K., Futaba, D. N., Mizuno, K., Namai, T., Yumura, M., and Iijima, S. (2004). Water-assisted highly efficient synthesis of impurity-free single-walled carbon nanotubes. Science 306, 1362. doi:10.1126/science.1104962

Hofmann, S., Cantoro, M., Kaempgen, M., Kang, D. J., Golovko, V. B., Li, H. W., et al. (2005). Catalyst patterning methods for surface-bound chemical vapour deposition of carbon nanotubes. Appl. Phys. A 81, 1559. doi:10.1007/ s00339-005-3338-6

Kim, S. M., Pint, C., Amama, P., Zakharov, D., Hauge, R., Maruyama, B., et al. (2009). Understanding growth termination of single-walled carbon nanotube carpets by documenting the evolution of catalyst morphology with the transmission electron microscope. Microsc. Microanal. 15, 1176. doi:10.1017/ S1431927609098456

Kleinsorge, B., Golovko, V. B., Hofmann, S., Geng, J., Jefferson, D., Jefferson, J., et al. (2004). Growth of aligned carbon nanotubes with colloidal catalysts at low temperatures over large areas. Chem. Commun. (Camb.) 1416. doi:10.1039/ b401785d

Kusunoki, M., Suzuki, T., Hirayama, T., Shibata, N., and Kaneko, K. (2000). A formation mechanism of carbon nanotube films on SiC (0001). Appl. Phys. Lett. 77, 531. doi:10.1063/1.127034

Li, Y., Kinloch, I., Shaffer, M. S. P., Windle, A. H., Geng, J., and Johnson, B. F. G. (2004). The growth of single-walled carbon nanotubes by the rapid heating of a supported catalyst. Chem. Mater. 16, 5637. doi:10.1021/cm0495111

Liu, B. L., Ren, W. C., Gao, L. B., Li, S. S., Pei, S. F., Liu, C., et al. (2009a). Metalcatalyst-free growth of single-walled carbon nanotubes. J. Am. Chem. Soc. 131, 2082. doi:10.1021/ja8093907

Liu, B. L., Ren, W. C., Liu, C., Sun, C. H., Gao, L. B., Li, S. S., et al. (2009b). Growth velocity and direct length-sorted growth of short single-walled carbon nanotubes by a metal-catalyst-free chemical vapor deposition process. ACS Nano 3 , 3421. doi: $10.1021 / \mathrm{nn} 900799 \mathrm{~V}$

Liu, B. L., Tang, D. M., Sun, C. H., Liu, C., Ren, W. C., Li, F., et al. (2011). Importance of oxygen in the metal-free catalytic growth of single-walled carbon nanotubes from SiOx by a vapor-solid-solid mechanism. J. Am. Chem. Soc. 133, 197. doi:10.1021/ja107855q

Mesgari, S., Sundramoorthy, A. K., Loo, L. S., and Chan-Park, M. B. (2014). Gel electrophoresis using a selective radical for the separation of single-walled carbon nanotubes. Faraday Discuss. 173, 351. doi:10.1039/c4fd00092g
Min, Y. S., Bae, E. J., Oh, B. S., Kang, D., and Park, W. (2005). Low-temperature growth of single-walled carbon nanotubes by water plasma chemical vapor deposition. J. Am. Chem. Soc. 127, 12498. doi:10.1021/ja054108w

Nasibulin, A. G., Brown, D. P., Queipo, P., Gonzalez, D., Jiang, H., and Kauppinen, E. I. (2006a). An essential role of $\mathrm{CO}_{2}$ and $\mathrm{H}_{2} \mathrm{O}$ during single-walled CNT synthesis from carbon monoxide. Chem. Phys. Lett. 417, 179. doi:10.1016/j. cplett.2005.10.022

Nasibulin, A. G., Queipo, P., Shandakov, S. D., Brown, D. P., Jiang, H., Pikhitsa, P. V., et al. (2006b). Studies on mechanism of single-walled carbon nanotube formation. J. Nanosci. Nanotechnol. 6, 1233. doi:10.1166/jnn.2006.340

Pint, C. L., Pheasant, S. T., Parra-Vasquez, A. N. G., Horton, C., Xu, Y. Q., and Hauge, R. H. (2009). Investigation of optimal parameters for oxide-assisted growth of vertically aligned single-walled carbon nanotubes. J. Phys. Chem. C 113, 4125. doi:10.1021/jp8070585

Rümmeli, M. H., Borowiak-Palen, E., Gemming, T., Pichler, T., Knupfer, M., Kalbac, M., et al. (2005). Novel catalysts, room temperature, and the importance of oxygen for the synthesis of single-walled carbon nanotubes. Nano Lett. 5, 1209. doi:10.1021/nl050692v

Rümmeli, M. H., Schäffel, F., Kramberger, C., Gemming, T., Bachmatiuk, A., Kalenczuk, R. J., et al. (2007). Oxide-driven carbon nanotube growth in supported catalyst CVD. J. Am. Chem. Soc. 129, 15772. doi:10.1021/ ja0779405

Schneider, J. J., Maksimova, N. I., Engstler, J., Joshi, R., Schierholz, R., and Feile, R. (2008). Catalyst free growth of a carbon nanotube-alumina composite structure. Inorganica Chim. Acta 361, 1770. doi:10.1016/j.ica.2006.10.025

Sundramoorthy, A. K., Mesgari, S., Wang, J., Kumar, R., Alam Sk, M., Yeap, S. H., et al. (2013). Scalable and effective enrichment of semiconducting single-walled carbon nanotubes by a dual selective naphthalene-based azo dispersant. J. Am. Chem. Soc. 135, 5569. doi:10.1021/ja312282g

Takagi, D., Hibino, H., Suzuki, S., Kobayashi, Y., and Homma, Y. (2007). Carbon nanotube growth from semiconductor nanoparticles. Nano Lett. 7, 2272. doi:10.1021/nl0708011

Tohji, K., Goto, T., Takahashi, H., Shinoda, Y., Shimizu, N., Jeyadevan, B., etal. (1996). Purifying single-walled nanotubes. Nature 383, 679. doi:10.1038/383679a0

Wen, Q., Qian, W., Wei, F., and Ning, G. (2007). Oxygen-assisted synthesis of SWNTs from methane decomposition. Nanotechnology 18, 215610.

Yamada, T., Maigne, A., Yudasaka, M., Mizuno, K., Futaba, D. N., Yumura, M., et al. (2008). Revealing the secret of water-assisted carbon nanotube synthesis by microscopic observation of the interaction of water on the catalysts. Nano Lett. 8, 4288. doi:10.1021/nl801981m

Zhang, G., Mann, D., Zhang, L., Javey, A., Li, Y., Yenilmez, E., et al. (2005). Ultrahigh-yield growth of vertical single-walled carbon nanotubes: hidden roles of hydrogen and oxygen. Proc. Natl. Acad. Sci. U.S.A. 102, 16141. doi:10.1073/ pnas. 0507064102

Conflict of Interest Statement: The authors declare that the research was conducted in the absence of any commercial or financial relationships that could be construed as a potential conflict of interest.

Copyright $\odot 2016$ Geng, Motta, Engels, Luo and Johnson. This is an open-access article distributed under the terms of the Creative Commons Attribution License (CC $B Y$ ). The use, distribution or reproduction in other forums is permitted, provided the original author(s) or licensor are credited and that the original publication in this journal is cited, in accordance with accepted academic practice. No use, distribution or reproduction is permitted which does not comply with these terms. 